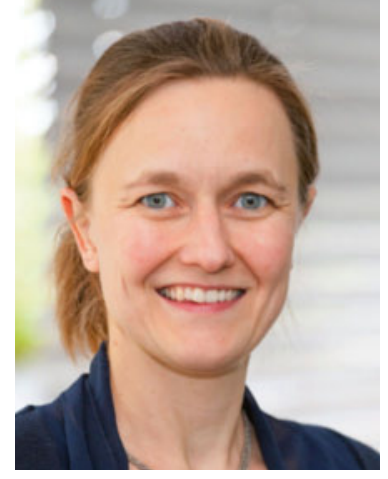

\title{
Beruf oder Berufung?
}

Eine gute Ausbildung, Talent, Fleiß und Glück - all das ist wichtig für einen erfolgreichen Beruf. Doch richtig gut ist nur, wer gerne zur Arbeit geht und Leidenschaft mitbringt. Im Idealfall ist der Beruf eine Berufung, und toll ist es, wenn wir bei dem Satz „Ich liebe es“ nicht an ein gelbes M, sondern an unseren Job denken.

Wenn ich meinen - rein subjektiven - Beobachtungen Glauben schenken kann, dann ist die Physiotherapie ein Beruf mit hohem Berufungspotenzial. Zahlreiche engagierte, hochmotivierte und erfolgreiche Therapeuten behandeln weltweit ihre Patienten mit Freude und Leidenschaft und erforschen die Wirkungsweisen unserer Therapiemethoden. Natürlich weiß ich, dass der Blick auf den Gehaltszettel vielen Physiotherapeuten Tränen in die Augen treibt - aber schließen Sie diese doch immer mal wieder und erinnern Sie sich, warum Sie Ihren Beruf gewählt haben. Hoffentlich lautet die Antwort dann: Weil ich es liebe.

Auch in dieser Ausgabe finden Sie wieder viele Beispiele, warum wir den schönsten Beruf der Welt haben. Schauen Sie doch mal auf Seite 26 und Seite 54. Viel Spaß beim Lesen wünscht Ihnen Ihre
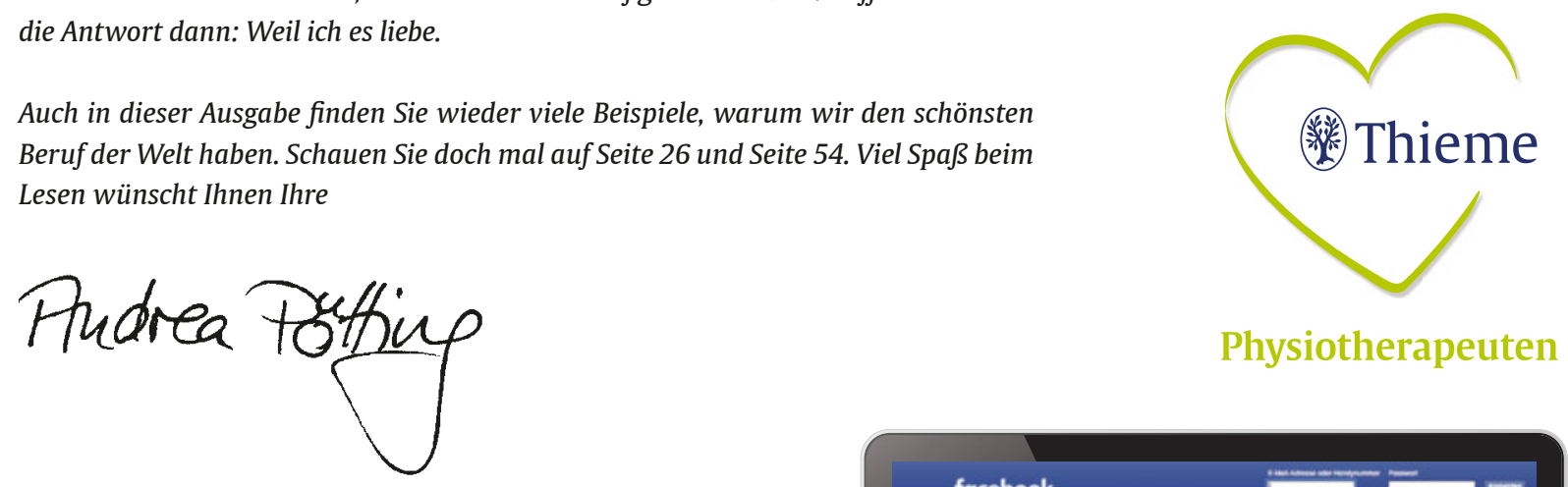

Wenn Liebe im Spiel ist, geht vieles leichter. Nicht ohne Grund heißt unsere Facebook-Seite „Thieme liebt Physiotherapeuten“. Einfach anmelden und sich immer wieder begeistern lassen!

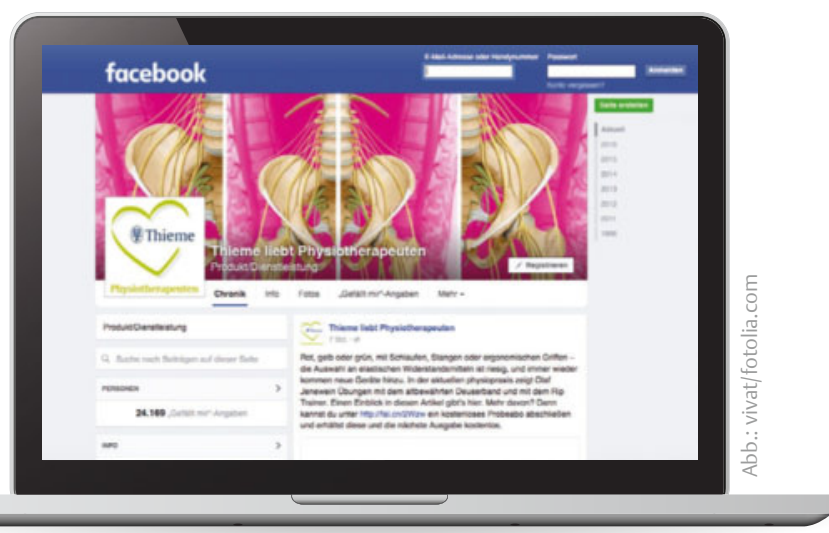

